\title{
Composite magnetostrictive materials for advanced automotive magnetomechanical sensors
}

\author{
R. W. McCallum, K. W. Dennis, D. C. Jiles, J. E. Snyder, and Y. H. Chen \\ Ames Laboratory, Iowa State University, Ames, Iowa 50011, USA \\ E-mail: mccallum@ameslab.gov
}

Received January 24, 2001

\begin{abstract}
In this paper we present the development of a composite magnetostrictive material for automotive applications. The material is based on cobalt ferrite, $\mathrm{CoO} \cdot \mathrm{Fe}_{2} \mathrm{O}_{3}$, and contains a small fraction of metallic matrix phase that serves both as a liquid phase sintering aid during processing and enhances the mechanical properties over those of a simple sintered ferrite ceramic. In addition the metal matrix makes it possible to braze the material making the assembly of a sensor relatively simple. The material exhibits good sensitivity and should have high corrosion resistance while at the same time it is low cost.
\end{abstract}

PACS: $75.80 .+q$

\section{Introduction}

The need for non-contact torque sensors has sparked considerable interest in developing new magnetomechanical sensor materials [1-5]. Highly magnetostrictive materials, such as Terfenol $\left(\mathrm{Tb}_{0.3} \mathrm{Dy}_{0.7} \mathrm{Fe}_{2}\right)$ [6], $\mathrm{SmFe}_{2}$ [7] and other rareearth-iron compounds have been considered as candidates for such applications. These materials have very high saturation magnetostrictions (1000$3000 \mathrm{ppm}$ ) [6], and might reasonably be expected to have high sensitivity of magnetization to stress and therefore be suitable for magnetomechanical sensor applications. Maraging steel has been considered an alternative sensor material by Garshelis [2]. Co-ferrite and metal-bonded Co-ferrite composites have recently been investigated by the authors as an alternative to existing materials competing for use in automotive and other torque sensing applications. The materials are inexpensive and non-corroding, and the metal-bonded Co-ferrite composites are mechanically robust and can be attached (e.g., by brazing) to metal parts. They show a steep slope of magnetostriction at low applied fields, $(d \lambda / d H)_{\sigma}$, which contributes to a high sensitivity of magnetic induction to stress, hence giving high signal-to-background noise ratios in sensor applications.

This overview will show the investigation and comparison of several composites based on existing materials (Table 1) and will discuss the design of a new composite material appropriate for these applications. The objective of this work was to develop a new type of magnetoelastic material with high magnetomechanical coefficient $d M / d \sigma$, relatively low anisotropy and high shear strength, low cost and good corrosion resistance. This material was primarily designed for automotive applications, as this is the area it may have the most immediate impact. It may also be applied to other torque sensing applications. Automobile sensors are often

Table 1

Magnetostriction, anisotropy and Curie temperature of selected materials

\begin{tabular}{c|c|c|c|c|c}
\hline \hline \multirow{2}{*}{ Material } & $\lambda_{100}$ & $\lambda_{111}$ & $\lambda_{s}$ & $K_{1}$, & $T_{c}$, \\
\cline { 2 - 4 } & \multicolumn{3}{|c|}{$10^{-6}$} & $10^{3} \mathrm{~J} / \mathrm{m}^{3}$ & $\mathrm{~K}$ \\
\hline \hline Iron [1] & 21 & -21 & & 47 & 1043 \\
Nickel [8] & -46 & -24 & -33 & -59 & 631 \\
CoO·Fe $_{2} \mathrm{O}_{3}[1]$ & $-920^{*}$ & $180^{*}$ & $-260^{*}$ & $60^{*}$ & 793 \\
$\mathrm{TbFe}_{2}[6]$ & & & 1753 & $>1000$ & 700 \\
SmFe $_{2}$ [6] & & & -1560 & & 676 \\
Terfenol-D [8] & 90 & 640 & $\sim 1000$ & 60 & $650-700$ \\
\hline \hline
\end{tabular}

* These values are sensitive to the exact stoichiometry, $\mathrm{Co} / \mathrm{Fe}$ ratio and heat treatments. 
required to operate under harsh environments such as temperatures ranging from $-40^{\circ} \mathrm{C}$ to $150^{\circ} \mathrm{C}$. All «on board» sensors are liable to be subjected to unexpected mechanical shocks which can be as high as 500 newtons and vibration levels of 150 newtons, and still be expected to function. The design of automobile sensors also needs to take into account that such sensors must function reliably for typically 10 years, or 100,000 miles, without intervention or failure. They must not be susceptible to spurious inputs and should be self-calibrating to compensate for short-term fluctuations or long term drift in performance. In the case of torque detection this problem had not yet been adequately solved, but there is a class of highly magnetostrictive magnetic materials that seem ideally suited to meet these needs. The magnetostrictive response of the material is well beyond the immediate requirements for torque sensors for advanced steering systems, however progress needs to be made in fabricating the material with the necessary mechanical strength, and at an acceptable cost. This work has explored the solutions to these questions and has identified and developed a suitable material for use in sensors for electronic control in advanced steering systems.

The new material identified and developed in this work will enable automobile manufacturers to move beyond the current outdated and fuel inefficient hydraulic power steering systems to advanced, electronically-operated power steering assists. To achieve this a new type of sensor is required which can reliably detect torque over the range $0-10 \mathrm{~N} \cdot \mathrm{m}$ with an accuracy of $1 \%$. U.S. automotive manufacturers have calculated that electronic steering systems will lead immediately to a 5\% improvement in fuel efficiency. This research will therefore directly help manufacturers to meet new U.S. guidelines on improved fuel efficiency.

Some materials such as Terfenol have magnetomechanical sensitivity well beyond the requirements for torque sensors that have been suggested by others [1,2]. However, the materials do not meet the requirements for mechanical strength corrosion resistance and cost. In order to meet these sensor specifications a significant degradation of magnetomechanical response is acceptable. One way to achieve this was to produce composite magnetostrictive material with the magnetostrictive material embedded in a rigid matrix material, which has the required mechanical strength. Selection of an appropriate matrix material also allows the cost of the sensor to be reduced by limiting the amount of costly rare earth material needed to fabricate a sensor.

Initially diluting the Terfenol with an iron matrix was attractive because the presence of a high permeability matrix could enhance the overall permeability of the material thereby improving the magnetomechanical response, and iron powder is very inexpensive when compared to the Terfenol it would be used to dilute. This idea was discarded both because of problems arising from the reaction between the iron matrix and the rare-earth metals when the powders were sintered and also because of problems related to the difference between the elastic moduli of the component materials. A number of alternative approaches were investigated in preliminary research, but none of these proved completely satisfactory. These included altering the chemical compositions to reduce the chemical reaction between the magnetostrictive particles and the matrix material, while still providing an iron-based matrix after sintering. None of these approaches resulted in materials with suitable magnetic properties. The use of epoxy bonded materials was also investigated, but these did not have adequate mechanical properties. A number of different dilutants for the expensive Terfenol component were also investigated. Finally metal-bonded cobalt ferrite was identified as a suitable choice for such sensors. These materials have a larger values of the derivative $d \lambda / d H$ than Terfenol-based composites, even though the saturation magnetostriction $\lambda_{s}$ is lower than in Terfenol.

\section{Experimental details}

The Terfenol-based composites were prepared by blending powders in an argon atmosphere. The composition of particles used in this study was $\mathrm{Tb}_{0.3} \mathrm{Dy}_{0.7} \mathrm{Fe}_{2}$ while the matrix materials consisted of metal and glass (soda-lime and phosphate), and resin. The metals were $\mathrm{Fe}, \mathrm{Cu}, \mathrm{Al}$ or $\mathrm{CeFe}_{2}$. Blended powder was poured into a $6 \mathrm{~mm}$ diameter die, pressed at 1 to $3 \mathrm{kN}$ under an inert argon atmosphere and heated at $10^{\circ} \mathrm{C} / \mathrm{min}$ to $300-900^{\circ} \mathrm{C}$ depending on the matrix material. The load was removed and the material cooled to ambient temperature while still under the argon atmosphere.

Cobalt ferrite was prepared by blending stoichiometric amounts of fine, high purity cobalt oxide and iron oxide powders in a ball mill, then firing at $1100^{\circ} \mathrm{C}$ for 72 hours in flowing dry air to form the compound. The powder was then milled to $<38 \mu \mathrm{m}$ and blended with chosen ratios of submicron metal powders ( $\mathrm{Ag}, \mathrm{Ni}, \mathrm{Co}$ ). These powder mixtures were cold pressed into shapes and sintered at up to $1450^{\circ} \mathrm{C}$. The resulting samples were typi- 
cally cylinders of $5 \mathrm{~mm}$ diameter and $10-15 \mathrm{~mm}$ length. Coercivity and saturation magnetization were also measured on one of the samples. The specimen of composition 98 vol. $\% \mathrm{CoO} \cdot \mathrm{Fe}_{3} \mathrm{O}_{3}+$ 2 vol. $\% \mathrm{Ag}_{0.97} \mathrm{Ni}_{0.03}$ and dimensions $2 \times 2 \times 4.5 \mathrm{~mm}$ was measured along its long axis in a Quantum Design MPMS SQUID magnetometer.

All magnetostriction data in the present work were measured using strain gauges. The samples were cut in cylinders of $5 \mathrm{~mm}$ diameter and $10 \mathrm{~mm}$ length. Fine emery cloth (600 grit) was used to abrade the side surface of each cylindrical sample. One flat side face of $3.5 \mathrm{~mm}$ wide was obtained for bonding with a strain gage. Special adhesives were used to secure a good contact between the sample and the gages.

The magnetic field was applied parallel along the cylindrical axis of the specimens, and the strain was measured along the same direction as the field was cycled in order to change the magnetization from positive saturation, through zero to negative saturation, then back through zero to positive saturation again. The magnetic field was measured using a standard Hall effect probe. Maximum magnetic field strength of $2 \mathrm{MA} / \mathrm{m}$ was applied to saturate the samples.

A magnetic torque sensor test bed was developed as part of the present investigation, and this was used to make the magnetomechanical measurements under torsional strain. The test bed provided pure applied torque with no associated bending moment, from $-10 \mathrm{~N} \cdot \mathrm{m}$ (counter clockwise, CCW) to $+10 \mathrm{~N} \cdot \mathrm{m}$ (clockwise, CW) using a computer-controlled servo-motor. The precision of the applied torque was $0.05 \mathrm{~N} \cdot \mathrm{m}$. It was measured and monitored by a commercial torque sensor. An applied magnetic field up to $\pm 2500 \mathrm{~A} / \mathrm{m}$ could be generated by a Helmholtz coil. The external magnetic field near the sample surface was measured by a Hall effect element, on a holder which could position it close to the sample, with its plane either horizontally (to measure axial field) or vertically (to measure circumferential field).

In a typical measurement, the applied torque was changed and the magnetic response measured. This included either the change of surface magnetic field or magnetic induction of the specimen. Using the program, both major loops (either surface magnetic field vs. torque or $B$ vs. $H$ ), as well as minor loops were measured. In a major loop, the applied field $H$ or torque (horizontal axis) only reversed direction at its maximum magnitude, i.e. the applied field/torque was increased from zero to the positive maximum, then reversed to negative maximum and back to zero. One major loop is referred to as a cycle. For minor loops, the value of horizontal axis reversed its direction at intermediate values.

Magnetomechanical torque response measurements were performed at different temperatures, using a temperature controlled fluid bath. A stirring propeller was used to increase the fluid circulation and improve the temperature homogeneity. The liquid was cooled by the cooling probe of a commercial chiller. The lowest temperature of this chiller was $-80^{\circ} \mathrm{C}$. In order to obtain good fluid circulation, a fluid with a low freezing point $\left(<-50^{\circ} \mathrm{C}\right)$ and low viscosity was needed. An ethanol-water solution (75 vol.\% ethanol + 25 vol.\% water) was chosen. The sample could be cooled down to $-37^{\circ} \mathrm{C}$ in $4 \mathrm{~h}$. The changes of external axial magnetic fields were measured as a function of applied torque (torque response) in the range of $-37^{\circ} \mathrm{C}$ to $23^{\circ} \mathrm{C}$.

Measurements between ambient temperature and $90^{\circ} \mathrm{C}$ were performed with the sample immersed in water heated in a separate tank, and circulated using a centrifugal pump. The torque response was measured at each preset point before it was heated to the next higher temperature. During each measurement, the temperature was kept constant to within $\pm 0.2^{\circ} \mathrm{C}$, which was monitored using two thermocouples. Finally, the torque response was measured after the sample had cooled back down to $22^{\circ} \mathrm{C}$.

In order to compare the temperature dependences between magnetomechanical hysteresis and $M-H$ hysteresis, $M-H$ hysteresis loops were also measured in the temperature range from $-40^{\circ} \mathrm{C}$ to $100^{\circ} \mathrm{C}$, using the Quantum Design MPMS SQUID magnetometer.

\section{Results}

\section{Terfenol-based composites}

Terfenol-based composites were considered a potential solution to lower the cost and to strengthen the material while maintaining adequate magnetostriction. Considering the chemical compatibility, a soda-lime glass matrix was chosen to bond the Terfenol particles. The magnetostrictions of this series of composites with different weight fractions of Terfenol are shown in Fig. 1,a. Compared with polycrystalline Terfenol, the composites exhibited much lower magnetostriction and particularly a lower $d_{33}$ coefficient $(d \lambda / d H)$ at low applied field. The presence of the second phase is thought to enhance domain wall pinning, thus inhibiting magnetization changes and reducing the initial permeability $[8,9]$, while also reducing the volume 

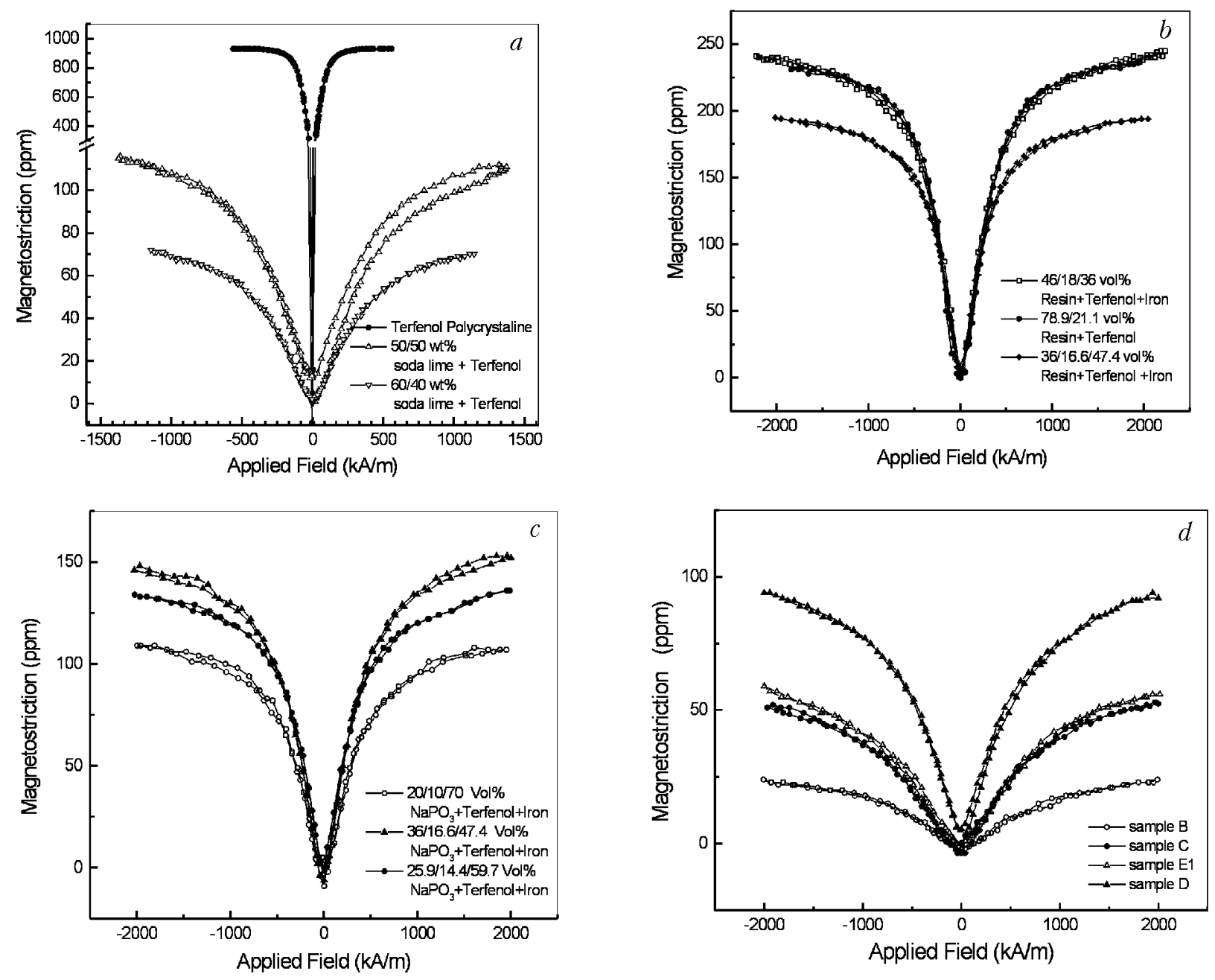

Fig. 1. Magnetostriction of Terfenol composites in soda lime matrix $(a)$, in resin matrix $(b)$, in Fe and $\mathrm{NaPO}_{3}$ matrix at low processing temperatures $\left(<600^{\circ} \mathrm{C}\right)(c)$, and of several composites with equal volume fractions of Terfenol particles in different matrix materials $(d)$.

fraction of material contributing to the magnetostriction.

While composites with soda-lime glass matrix exhibited moderate saturation magnetostrictions (70-120 ppm), they appeared to be very porous and had inadequate mechanical properties. It also required a relatively large fraction (40 wt.\%50 wt.\%) of Terfenol to get acceptable levels of magnetostriction ( $>100 \mathrm{ppm})$. Therefore, these materials are not considered ideal candidates for magnetostrictive sensor applications.

Terfenol + resin. Subsequently, polymer (resin) matrix materials were investigated. Embedding the Terfenol in a resin matrix can form a composite with low porosity, which does not degrade the magnetic properties of the Terfenol phase through chemical reaction. The results are shown in Fig. 1, 8 . With 16-21 vol.\% Terfenol in those composites, saturation magnetostrictions ranging from 200 to $250 \mathrm{ppm}$ were measured. Nevertheless, the mechan- ical properties (plastic deformation, creep, low tensile strength, low Young's modulus) of the resin are of questionable value for the application. Also, field strengths higher than $2 \mathrm{MA} / \mathrm{m}$ were needed to achieve the saturation magnetostrictive strains, which implies that $d \lambda / d H$ at low field was still too small.

Terfenol $+\mathrm{NaPO}_{3}$ glass. A series of samples with different volume fractions of Terfenol in the same matrix material, $\mathrm{NaPO}_{3}$ glass, were measured.

Terfenol + iron $+\mathrm{NaPO}_{3}$ glass. Samples were also prepared with Terfenol in an iron $+\mathrm{NaPO}_{3}$ glass matrix. At processing temperatures lower than $600^{\circ} \mathrm{C}$, adequate saturation magnetostriction was obtained $(100 \sim 150 \mathrm{ppm})$, but final samples were porous. The results of Fig. 1,c show that the magnetostriction increased with increasing volume fraction of Terfenol. In order to improve the density of the composites, the processing temperatures were increased to $900^{\circ} \mathrm{C}$. This process produced solid 
samples but, the measured magnetostrictions were as low as $10-15 \mathrm{ppm}$. One of our hypotheses as to the reason for this concerned the difference in elastic modulus between the (mostly $\mathrm{Fe}$ ) matrix and the magnetostrictive Terfenol.

In order to investigate the effect of the modulus of the matrix, a series of samples with a fixed volume fraction $(10 \%)$ of Terfenol in matrix materials with different elastic moduli were measured. Magnetostriction curves of the series of composite materials are shown in Fig. 1, $d$. The matrix materials were: $\mathrm{A}\left(\mathrm{Fe}+\mathrm{NaPO}_{3}\right), \quad \mathrm{B}\left(\mathrm{Cu}+\mathrm{NaPO}_{3}\right)$, $\mathrm{C}\left(\mathrm{Al}+\mathrm{NaPO}_{3}\right), \quad \mathrm{D}\left(\mathrm{CeFe}_{2}+\mathrm{NaPO}_{3}\right), \quad \mathrm{E}\left(\mathrm{NaPO}_{3}\right)$. Magnetostriction of sample A was too low to be shown in the same figure. The Young's modulus of iron, copper, aluminum, $\mathrm{NaPO}_{3}$ glass, and $\mathrm{CeFe}_{2}$ are known to be $220,110,69,50$, and $30 \mathrm{MPa}$, respectively [10], compared to Young's modulus of Terfenol, which is $30 \mathrm{MPa}$. These results show that the magnetostriction of the composite material increased with decreasing elastic modulus of the matrix.

Summary of magnetostriction of Terfenol-based composites. Based on the above results, it appears that the elastic modulus of the matrix has a strong impact on the magnetostriction of magnetostrictive composites. The measured saturation magnetostriction decreased from $90 \mathrm{ppm}$ to a value of $15 \mathrm{ppm}$ in composites with matrices with different elastic modulus. Higher elastic modulus was found to lead to lower magnetostriction.

Table 2

Magnetostriction of $\mathrm{CoO} \cdot \mathrm{Fe}_{2} \mathrm{O}_{3}$ and various composites bonded with metals

\begin{tabular}{c|c}
\hline \hline Composition & $\begin{array}{c}\text { Maximum } \\
\text { magnetostriction, } \\
\text { ppm }\end{array}$ \\
\hline \hline $100 \% \mathrm{CoO} \cdot \mathrm{Fe}_{2} \mathrm{O}_{3}$ & -225 \\
$2 / 98 \mathrm{vol} \% \mathrm{Ag}_{0.1} \mathrm{Ni}_{0.9}+\mathrm{CoO} \cdot \mathrm{Fe}_{2} \mathrm{O}_{3}$ & -168 \\
$2 / 98 \mathrm{vol} \% \mathrm{Ag}_{0.5} \mathrm{Ni}_{0.5}+\mathrm{CoO} \cdot \mathrm{Fe}_{2} \mathrm{O}_{3}$ & -195 \\
$2 / 98 \mathrm{vol} \% \mathrm{Ag}_{0.8} \mathrm{Ni}_{0.2}+\mathrm{CoO} \cdot \mathrm{Fe}_{2} \mathrm{O}_{3}$ & -210 \\
$2 / 98 \mathrm{vol} \% \mathrm{Ag}_{0.97} \mathrm{Ni}_{0.03}+\mathrm{CoO} \cdot \mathrm{Fe}_{2} \mathrm{O}_{3}$ & -233 \\
$2 / 98 \mathrm{vol} \% \mathrm{Ag}_{0.98} \mathrm{Ni}_{0.02}+\mathrm{CoO} \cdot \mathrm{Fe}_{2} \mathrm{O}_{3}$ & -205 \\
$1 \mathrm{vol} \% \mathrm{Co}+\mathrm{CoO} \cdot \mathrm{Fe}_{2} \mathrm{O}_{3}$ & -155 \\
$2 \mathrm{vol} \% \mathrm{Co}+\mathrm{CoO} \cdot \mathrm{Fe}_{2} \mathrm{O}_{3}$ & -80 \\
$5 \mathrm{vol} \% \mathrm{Co}+\mathrm{CoO} \cdot \mathrm{Fe}_{2} \mathrm{O}_{3}$ & -25 \\
\hline \hline
\end{tabular}

Composites with $\mathrm{NaPO}_{3}$ glass matrix provided high magnetostriction/Terfenol fraction ratio together with good mechanical properties. However, initial piezomagnetic coefficients $d \lambda / d H$ of all the Terfenol-based composites are low. In addition, 30 vol.\% Terfenol is needed to obtain $200 \mathrm{ppm}$ in $\mathrm{NaPO}_{3}$ glass matrix composites, and as a rare earth intermetallic, the high content of rare earth metal makes the material expensive and extremely susceptible to corrosion.

\section{Magnetostriction of cobalt ferrite and its composites}

A search for a corrosion resistant, inexpensive material which matched the magnetic and mechanical properties of Terfenol revealed that polycrystalline Co ferrite $\left(\mathrm{CoO} \cdot \mathrm{Fe}_{2} \mathrm{O}_{3}\right)$ exhibits high magnetostriction $(\sim 200 \mathrm{ppm})$ at room temperature. However, due to porosity [11], and relatively low fracture strength, its applications have been restricted [12]. In order to overcome this problem a study involving metallic binders or sintering aids was undertaken. $\mathrm{Ag} / \mathrm{Ni}, \mathrm{Ag} / \mathrm{Co}$, or Co was used in order to bind the ferrite together [13]; Ag, which has a low oxygen affinity, has the advantage of not chemically reducing the ferrite. However, Ag does not wet the ferrite properly during fabrication. The addition of other elements such as Ni or Co greatly enhances the wetting properties. This wetting improves the mechanical properties of the Co ferrite by producing a stronger bond. However the presence of transition magnetic metals $(\mathrm{Co} / \mathrm{Ni})$ could also change the magnetic properties of the Co ferrite composite by changing either the transition metal or oxygen content of the material.

Maximum magnetostrictions of Co ferrite and selected metal-bonded Co-ferrite composites are listed in Table 2. While some of the metal-bonded composites have lower peak magnetostrictions than pure $\mathrm{CoO} \cdot \mathrm{Fe}_{2} \mathrm{O}_{3}$, they generally offer better mechanical properties with fracture strength higher than $69 \mathrm{MPa}(10 \mathrm{ksi})$. Co ferrite, being an oxide, has the additional advantage of excellent corrosion resistance.

The piezomagnetic coefficient (slope of the magnetostriction curve, $(\partial \lambda / \partial H)_{\sigma}$ at low field) is another important parameter of magnetostrictive materials, especially for sensor applications [10]. Magnetostriction curves are shown in Fig. 2 for a series of 98 vol. $\%$ Co ferrite +2 vol. $\% \mathrm{Ag}_{1-x} \mathrm{Ni}_{x}$ for various values of $x$. A magnetostriction curve for $100 \%$ Co ferrite is shown for comparison. With careful adjustment of the composition of metal fraction of $\mathrm{Ag} / \mathrm{Ni}(97 \% \mathrm{Ag}$ and $3 \% \mathrm{Ni})$, higher 


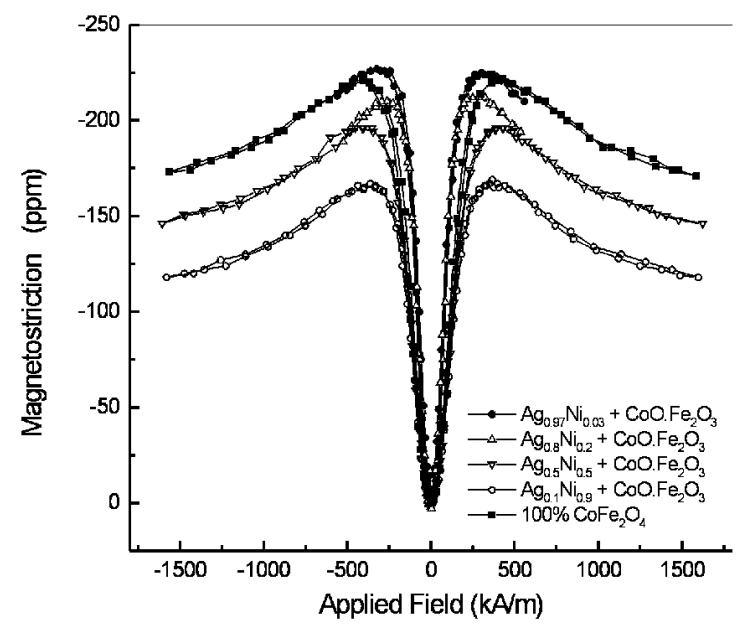

Fig. 2. Magnetostrictions of 98 vol.\% Co ferrite +2 vol. $\%$ $\mathrm{Ag}_{1-x} \mathrm{Ni}_{x}$ for various values of $x .100 \%$ Co ferrite is shown for comparison.

low-field piezomagnetic coefficients, together with comparable peak magnetostriction to Co ferrite were obtained.

Magnetostriction curves of another series of $\mathrm{Co}^{-}$ ferrite composites $\left(\mathrm{CoO} \cdot \mathrm{Fe}_{2} \mathrm{O}_{3}+\mathrm{Co}\right)$ are shown in Fig. 3. While these composites have lower peak magnetostriction than pure $\mathrm{CoO} \cdot \mathrm{Fe}_{2} \mathrm{O}_{3}$, some of them exhibit higher initial piezomagnetic coefficients $d \lambda / d H$. The results show that the saturation magnetostriction decreased as the Co volume percentage increased from 0 to $5 \%$ while the Co additive increased the sensitivity to magnetic field, $d \lambda / d H$.

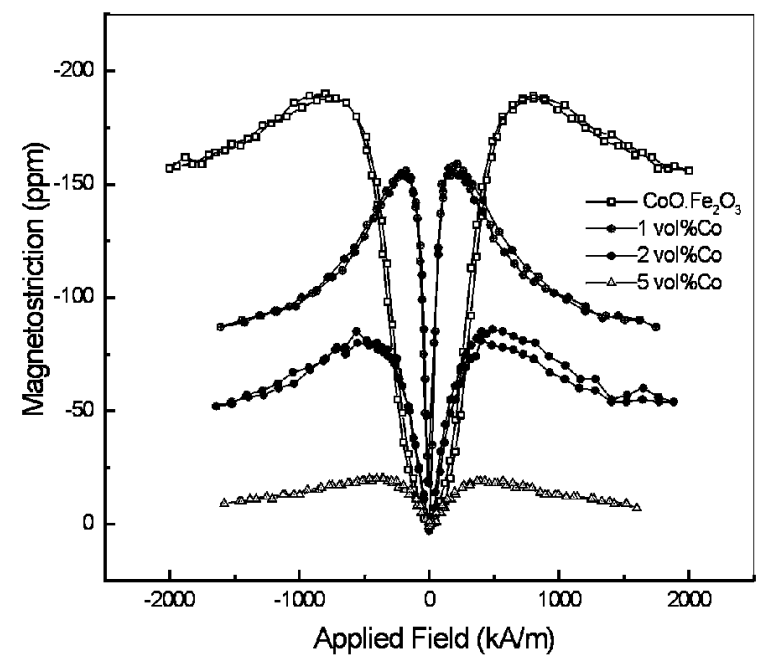

Fig. 3. Magnetostriction of Co-ferrite composites bonded with various amounts of Co additive.
In order to analyze the magnetostriction properties of metal-bonded Co-ferrite composites, the hysteresis loops were measured. The metal-bonded Coferrite composites generally exhibited coercivities in a range of $6-8 \mathrm{kA} / \mathrm{m}$. This was much lower than that $(160 \mathrm{kA} / \mathrm{m})$ reported for Co ferrite [14-16]. The bonding metal may make it easier to nucleate reverse magnetic domains at the surface of the Co-ferrite particles, either by reacting with the ferrite and producing regions of reduced anisotropy, or by producing regions of a second magnetic material with lower anisotropy (e.g., Ni or Co) at the surface. From the magnetostriction point of view, this will increase the initial permeability, the initial piezomagnetic coefficient and hence the sensitivity to stress. At the same time, maximum magnetostriction of the composites is observed to decrease with increasing amounts of $\mathrm{Co}$ in the bonding metal, or increasing $\mathrm{Ni}$ in the $\mathrm{Ag} / \mathrm{Ni}$ bonding metal mixture. There are two possible mechanisms at work here. First, the Co or Ni could diffuse into the Co ferrite, changing the stoichiometry and thus the magnetostriction. Although the literature references on this effect are limited, Co-rich Co ferrite is reported to have lower magnetostriction and magnetic anisotropy [17]. One would also expect that addition of $\mathrm{Ni}$ to Co ferrite would also lower the magnetostriction. As the magnetostriction is also dependent on porosity and the mechanical strength of the bonding of the composite, it is possible that the changes in magnetostriction result from the mechanical properties of the composites.

\section{Comparison of magnetostriction in Terfenol-based and cobalt-ferrite composites}

For soft magnetic materials, the presence of a nonmagnetic second phase normally hinders the magnetization processes and decreases the piezomagnetic coefficient, $d \lambda / d H$ in low fields. However, the metal-bonded cobalt-ferrite composites appeared to have lower coercivity than the pure sintered ferrite. This attributed to the fact that both nickel and cobalt change the stoichiometry of the ferrite, and in particular the $\mathrm{Co} / \mathrm{Fe}$ ratio, and thereby decrease the anisotropy of $\mathrm{CoO} \cdot \mathrm{Fe}_{2} \mathrm{O}_{3}$ [18]. The magnetostriction of a typical Co-ferrite composite with a composition of 98 vol. $\% \mathrm{CoO} \cdot \mathrm{Fe}_{2} \mathrm{O}_{3}+2$ vol. $\% \mathrm{Ag}_{0.97} \mathrm{Ni}_{0.03}$ was comparable in magnitude to that of a Terfenol-based composite with 30 vol. $\%$ Terfenol +70 vol. $\% \mathrm{NaPO}_{3}$ (Fig. 4). $\mathrm{CoO} \cdot \mathrm{Fe}_{2} \mathrm{O}_{3}$ is known to have a cubic spinel crystal structure with magnetic easy axes along the $\mathrm{d}$ directions. The magnetostriction coefficients $\lambda_{100}$ and $\lambda_{111}$ have opposite signs, and the easy axis magnetostriction coefficient $\lambda_{100}$ is approximately 5 times 


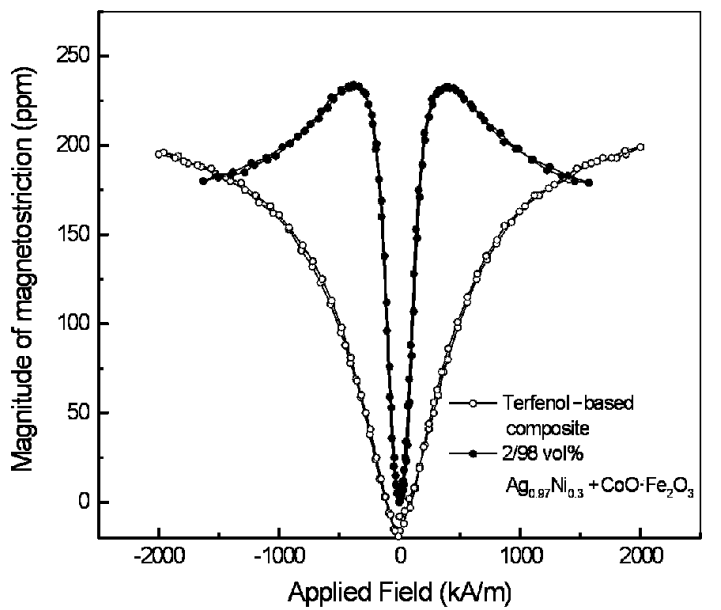

Fig. 4. Comparison of magnetostrictions of Co-ferrite composite and Terfenol composite.

the magnitude of $\lambda_{111}$ [19]. The measured magnetostriction of the $\mathrm{CoO} \cdot \mathrm{Fe}_{2} \mathrm{O}_{3}$ peaks at relatively low field $(200-300 \mathrm{kA} / \mathrm{m})$, then decreases with increasing field, as the magnetization of the particles first changes direction by $90^{\circ}$ domain wall processes, then is rotated away from easy directions.

This maximum at low applied field contrasts with that of the Terfenol-based composites, which only saturate at very high applied fields $\left(2 \cdot 10^{6} \mathrm{~A} / \mathrm{m}\right.$ or larger $)$. Co ferrite and its metalbonded composites also have strain derivatives $(d \lambda / d H)_{\sigma}$ of typically $1 \cdot 10^{-9} \mathrm{~A}^{-1} \cdot \mathrm{m}$, at low applied fields $(<100 \mathrm{kA} / \mathrm{m})$, which are comparable to those of polycrystalline Terfenol [20], and much larger than those of Terfenol-based composites, which had values of typically $0.2 \cdot 10^{-9} \mathrm{~A}^{-1} \cdot \mathrm{m}$.

The magnetostriction together with mechanical and corrosion properties of polycrystalline Terfenol, pure Co ferrite, Terfenol-based composites, and metal-bonded Co-ferrite composites are compared in Table 3. Although the single crystalline and polycrystalline Terfenol can provide even higher magne- tostriction (1000-2000 ppm), its cost is much higher than Co-ferrite composites. Furthermore, the mechanical and corrosive properties could not meet the requirements for sensor applications. The Terfenol-based composites studied in the present work lowered the cost and improved the mechancial properties. However, the low piezomagnetic coefficient $d \lambda / d H$ implies low stress sensitivity for torque sensing. Metal bonded Co ferrite exhibits the optimum combination of sufficient magnetostriction, high piezomagnetic coefficient, very good mechanical properties, corrosion resistance, and low cost. The prime characteristics of this series of materials appear promising for magnetomechanical sensing and actuating applications.

\section{Magnetomechanical effect measurements}

Selected compositions were pressed and sintered in the form of rings that were brazed on to stainless steel shafts. The response to torque was measured using the magnetic torque sensor test bed. All samples were magnetized circumferentially to remanence before the torque response was tested. To achieve this, the ferrite rings were rotated in the fringing field of a narrow-gap (1 mm) electromagnet while the field was decreased from $160 \mathrm{kA} / \mathrm{m}$ to zero. After being magnetized circumferentially, the changes of external axial magnetic fields, close to the surface at the midpoint along the axis, were measured as a function of applied torque in different routines (major, minor loops).

\section{Magnetomechanical effects under torsional stress of cobalt-ferrite composites}

Major loops. Two compositions of metal-bonded Co-ferrite composites were considered primary candidates for torque sensing applications. Composition of 98 vol. $\% \mathrm{CoO} \cdot \mathrm{Fe}_{2} \mathrm{O}_{3}+2$ vol. $\% \mathrm{Ag}_{0.97} \mathrm{Ni}_{0.03}$ exhibits the highest peak magnetostriction $(-30 \mathrm{ppm})$

Table 3

Comparison of Terfenol, Terfenol composite and Co-ferrite composite

\begin{tabular}{|c|c|c|c|c|c|}
\hline Sample & $\begin{array}{c}\text { Initial slope } \\
d \lambda / d H, 10^{-9} \mathrm{~A}^{-1} \cdot \mathrm{m}\end{array}$ & $\begin{array}{l}\text { Saturation magnetostriction, } \\
\qquad 10^{-6}\end{array}$ & $\begin{array}{l}\text { Cost / gr., } \\
\text { USD }\end{array}$ & $\begin{array}{l}\text { Mechanical } \\
\text { properties }\end{array}$ & $\begin{array}{l}\text { Corrosion } \\
\text { resistance }\end{array}$ \\
\hline Polycrystalline Terfenol & 1.3 & 1000 & 15.00 & Poor & Poor \\
\hline Terfenol-based composite (30 vol.\%) & 0.2 & 200 & 5.00 & Good & Good \\
\hline Sintered Co ferrite & 1.0 & 225 & 0.75 & Poor & Excellent \\
\hline Metal-bonded Co-ferrite composite* & 1.3 & 230 & 0.75 & Very good & Excellent \\
\hline
\end{tabular}

* Composition: 98 vol.\% CoO $\cdot \mathrm{Fe}_{2} \mathrm{O}_{3}+2$ vol. $\% \mathrm{Ag}_{0.97} \mathrm{Ni}_{0.03}$ 


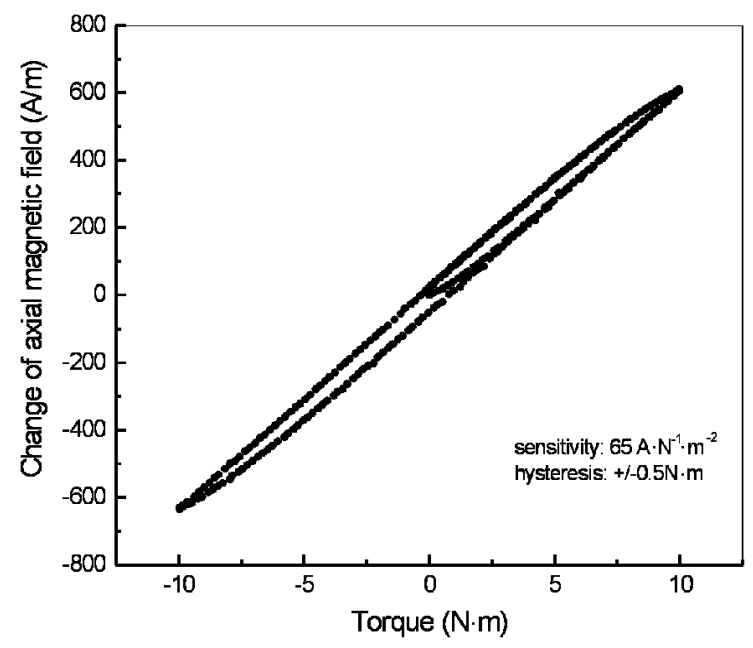

Fig. 5. Torque test of Co-ferrite composite (98 vol.\% $\mathrm{CoO} \cdot \mathrm{Fe}_{2} \mathrm{O}_{3}+2$ vol. $\% \mathrm{Ag}_{0.97} \mathrm{Ni}_{0.03}$ ) ring.

and the highest initial piezomagnetic coefficient of the series bonded with $\mathrm{Ag}_{1-x} \mathrm{Ni}_{x}$, while composition of 99 vol. $\% \mathrm{CoO} \cdot \mathrm{Fe}_{2} \mathrm{O}_{3}++1$ vol.\% $\mathrm{Co}$ exhibits the highest initial piezomagnetic coefficient $\left(2 \cdot 10^{-9} \mathrm{~A}^{-1} \cdot \mathrm{m}\right)$. Several samples were sintered in the shape of rings with different height/diameter ratios, and were then brazed onto stainless steel shafts. The performance of the former composition exhibited better stability due to its better brazability (bonding strength and uniformity) with stainless steel shafts.

The axial surface magnetic field of the prototype sensor was measured as a function of applied torque. Among those prototype sensors, the sample with dimensions of $25 \mathrm{~mm}$ OD, $12.5 \mathrm{~mm}$ ID, and $10 \mathrm{~mm}$ high offered the best performance (high sensitivity and low hysteresis). The performance of this prototype sensor is shown in Fig. 5.

In this study, magnetomechanical sensitivity $d H_{a} / d \tau$, is defined as the slope of the linear portion of the axial field vs. torque plot and the magnetomechanical hysteresis as half of the width in $\mathrm{N} \cdot \mathrm{m}$ of the major loop when $\Delta \mathbf{H}_{a}$ is zero. The magnetomechanical sensitivity was $65 \mathrm{~A} \cdot \mathrm{N}^{-1} \cdot \mathrm{m}^{-2}$ with a hysteresis of $+/-0.5 \mathrm{~N} \cdot \mathrm{m}$ within a major loop of $+/-10 \mathrm{~N} \cdot \mathrm{m}$. Considering the precision of the Hall probe is the $0.8 \mathrm{~A} / \mathrm{m}$. Sensitivity of $65 \mathrm{~A} / \mathrm{m}$ per $\mathrm{N} \cdot \mathrm{m}$ provides a sufficient signal to noise ratio.

Except for the magnetomechanical hysteresis, the prototype sensor showed better performance than Ni rods. Significantly it gave higher sensitivity, better repeatability, and wider torque range. The remanence of nickel depends on the residual stress which is not repeatable and its coercivity is small $(1600 \mathrm{~A} / \mathrm{m}$, as machined, $130 \mathrm{~A} / \mathrm{m}$, an-

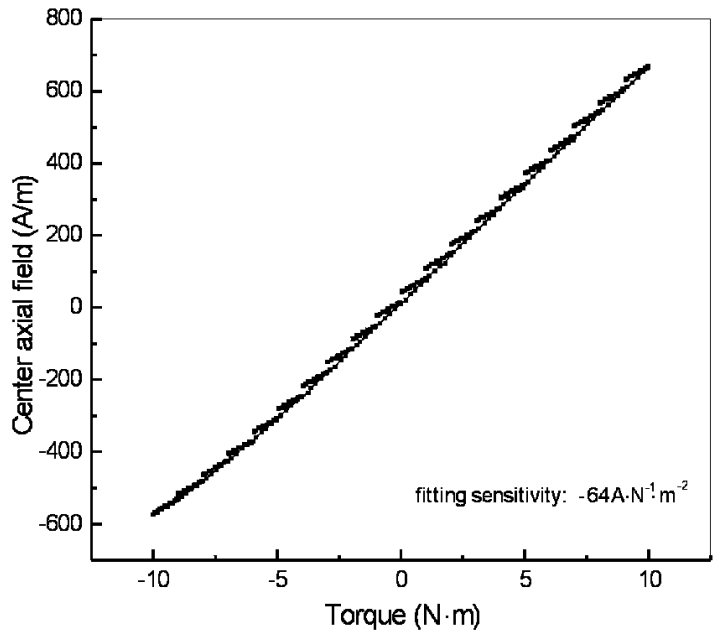

Fig. 6. Minor loops of the torque test. The measurements started from $-10 \mathrm{~N} \cdot \mathrm{m}$ and then cycled with a step size of $1 \mathrm{~N} \cdot \mathrm{m}$. After completing every cycle, the torque was increased to next cycle. The overall gradient of the curve is $d H / d \tau=-64 \mathrm{~A} / \mathrm{m}$ per $\mathrm{N} \cdot \mathrm{m}$.

nealed). On the other hand, the Co-ferrite composite (coercivity, $\sim 8 \mathrm{kA} / \mathrm{m}$ ) is magnetically much harder than Ni and thus the remanence state is much more stable. In addition, the circumferential magnetization direction is the preferred direction because it has low magnetostatic energy. Due to strong domain wall pinning in Co ferrite, domain wall bowing dominates the magnetization processes under torque. Thus, the magnetic field near the surface of a Co-ferrite ring sample did not decay after a few torque cycles. The hysteresis of the torque response mainly comes from the anisotropy and local variations of magnetic properties.

Minor loops. For practical applications, minor loops, (i.e., change in direction of torque at an arbitrary value rather than at the maximum of the range) occur much more frequently than a major loop, in which the torque just changes its direction at maximum torque values $( \pm 10 \mathrm{~N} \cdot \mathrm{m})$. In the present study, a particular set of minor loops were chosen for measurement. The measurement consisted of 20 minor loops, starting from $-10 \mathrm{~N} \cdot \mathrm{m}$, then cycled with a step size of $1 \mathrm{~N} \cdot \mathrm{m}$, and finally ended at $10 \mathrm{~N} \cdot \mathrm{m}$. The results are shown in Fig. 6. The response of surface magnetic field from the most recent torque reverse point returned to the major loop after $1 \mathrm{~N} \cdot \mathrm{m}$.

\section{Temperature dependence of magnetomechanical effects in cobalt ferrite under torsional stress}

The results of torque tests at $-37^{\circ} \mathrm{C}, 22^{\circ} \mathrm{C}$ and $80^{\circ} \mathrm{C}$ are shown in Fig. 7, $a-c$. The temperature dependence of the magnetomechanical sensitivity 

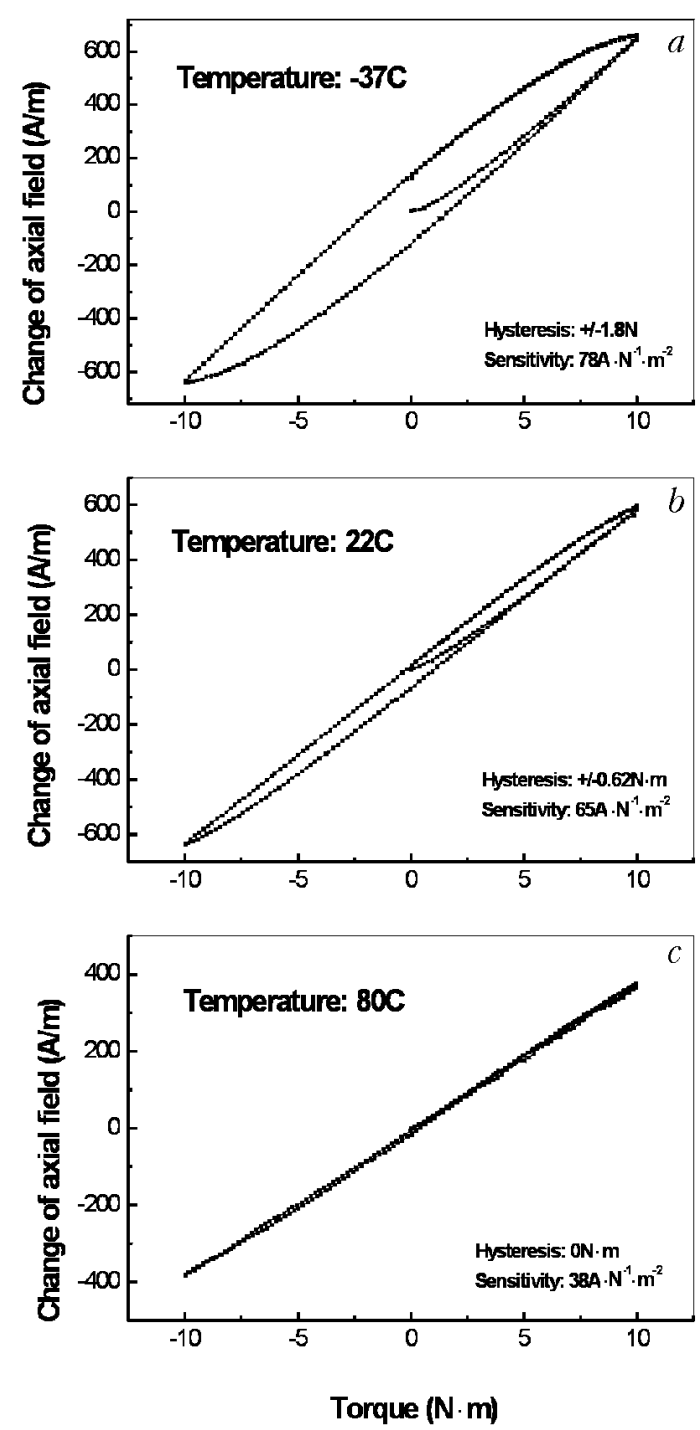

Fig. 7. The magnetomechanical torque responses at three typical temperatures $T,{ }^{\circ} \mathrm{C}:-37(a) ; 22($ b) $; 80(c)$.

and the magnetomechanical hysteresis over the range $-37^{\circ} \mathrm{C}$ to $90^{\circ} \mathrm{C}$ are plotted in Fig. 8. The magnetomechanical sensitivity decreased from $78 \mathrm{~A} \cdot \mathrm{N}^{-1} \cdot \mathrm{m}^{-2}$ at $-37^{\circ} \mathrm{C}$ to $65 \mathrm{~A} \cdot \mathrm{N}^{-1} \cdot \mathrm{m}^{-2}$ at $22^{\circ} \mathrm{C}$ and to $34 \mathrm{~A} \cdot \mathrm{N}^{-1} \cdot \mathrm{m}^{-2}$ at $90^{\circ} \mathrm{C}$. It decreased approximately linearly with increasing temperature as shown in Fig. 8. The decrease in sensitivity was $56 \%$ (on average $0.4 \%$ per ${ }^{\circ} \mathrm{C}$ ). The magnetomechanical hysteresis also decreased from $\pm 1.8 \mathrm{~N} \cdot \mathrm{m}$ to $\pm 0.62 \mathrm{~N} \cdot \mathrm{m}$ as the temperature increased from $-37^{\circ} \mathrm{C}$ to $22^{\circ} \mathrm{C}$ and to less than $\pm 0.1 \mathrm{~N} \cdot \mathrm{m}$ at $60^{\circ} \mathrm{C}$. Over the range $-37^{\circ} \mathrm{C}$ to $60^{\circ} \mathrm{C}$ the hysteresis decreased linearly with temperature giving a decrease of $0.02 \mathrm{~N} \cdot \mathrm{m}$ per ${ }^{\circ} \mathrm{C}$ (on average $1 \%$ per ${ }^{\circ} \mathrm{C}$ ). Interestingly, the magnetomechanical hysteresis remained close to zero as the temperature increased beyond $60^{\circ} \mathrm{C}$, giving a magnetomechanical response $d H_{a} / d \tau$ that was linear and reversible.

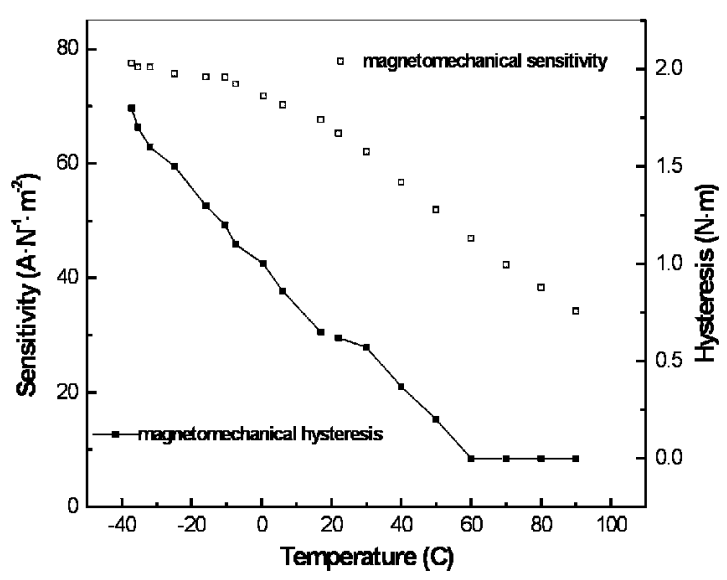

Fig. 8. The temperature dependence of the magnetomechanical effect of the ring-shaped Co-ferrite composite under torsional strain in the temperature range of $-37^{\circ} \mathrm{C}$ to $90^{\circ} \mathrm{C}$. The circles represent magnetomechanical sensitivity and the squares represent magnetomechanical hysteresis.

The torque response was also measured after the sample had been heated to $90^{\circ} \mathrm{C}$ and cooled back to $22^{\circ} \mathrm{C}$. The sensitivity and magnetomechanical hysteresis were $48 \mathrm{~A} \cdot \mathrm{N}^{-1} \cdot \mathrm{m}^{-2}$ and $\pm 0.6 \mathrm{~N} \cdot \mathrm{m}$, respectively. As a result of thermal cycling the sensitivity had decreased by about $26 \%$, while the magnetomechanical hysteresis returned to its earlier value. These results showed some significant thermal hysteresis in the sensitivity, while the magnetomechanical hysteresis appeared to be unaffected by thermal cycling.

$M-H$ hysteresis loops were measured over a similar temperature range as the magnetomechanical response. The coercivity, remanence, and saturation magnetization decreased with temperature in the range from $-40^{\circ} \mathrm{C}$ up to $100^{\circ} \mathrm{C}$, as shown in Fig. 9. The coercivity changed from 14.4 to $4.4 \mathrm{kA} / \mathrm{m}$ (a total of $69 \%$, or $0.5 \%$ per ${ }^{\circ} \mathrm{C}$ ), the remanent magnetization changed from 70 to $26.5 \mathrm{kA} / \mathrm{m}$ (a total of $62 \%$, or $0.44 \%$ per ${ }^{\circ} \mathrm{C}$ ), and the saturation magnetization changed from 445 to $387 \mathrm{kA} / \mathrm{m}$ (a total of $13 \%$, or $0.09 \%$ per ${ }^{\circ} \mathrm{C}$ ).

\section{Discussion}

Only a few previous studies have reported any results on the temperature dependence of magnetostriction or anisotropy of Co ferrites [16,19,21]. Due to the fact that the magnetizations of the sublattices of ferrites have opposite signs and different temperature dependence, the temperature dependence of the magnetic properties of ferrites, such as saturation magnetization and anisotropy can be complicated [13]. Metal-bonded Co ferrite composites are 


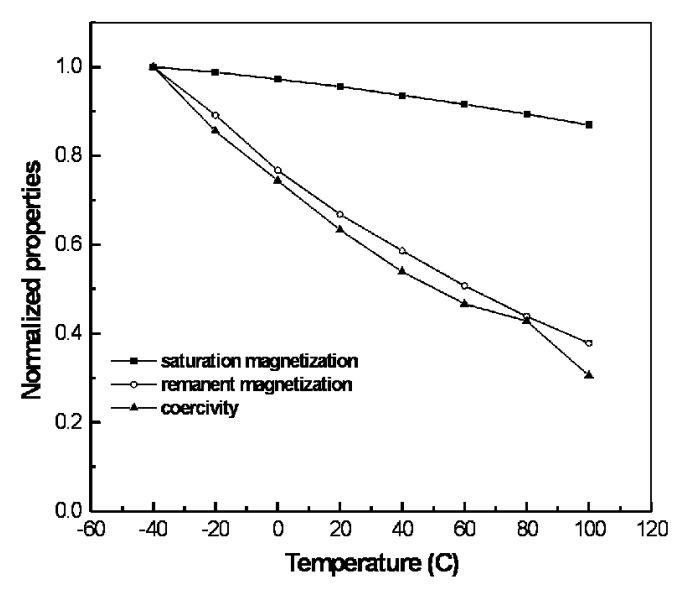

Fig. 9. The temperature dependence of coercivity, remanent magnetization and saturation magnetization of metal-bonded Co-ferrite composite. Saturation magnetization, remanent magnetization and coercivity are normalized by their values at $40^{\circ} \mathrm{C}$

even more complex systems due to the metal additives and different processing from pure Co-ferrite [20]. The temperature dependence can be explained by the changes of magnetostriction, anisotropy, spontaneous magnetization and pinning of domain walls caused by the availability of increased thermal energy.

It is known that the sensitivity of the magnetomechanical effect is related to magnetostriction [22]. The temperature dependence of magnetostriction was investigated by Guillaud [16], where it was reported that Co ferrite exhibited magnetostrictions of $-270,-190$, and $-110 \mathrm{ppm}$ at $-196,-80$, and $20^{\circ} \mathrm{C}$, respectively. The magnitude of magnetostriction decreased approximately linearly from $196^{\circ} \mathrm{C}$ to room temperature with an average decrease of magnetostriction of $0.4 \%$ per ${ }^{\circ} \mathrm{C}$. The change of magnetostriction plays an important role in the temperature dependence of the magnetomechanical effect. A decrease in magnetostriction with increasing temperature indicates a decreasing magnetomechanical coupling strength, which could cause a decrease in magnetomechanical response with increasing temperature.

Although the Curie temperature of Co ferrite is $520^{\circ} \mathrm{C}$, the saturation magnetization decreases significantly as the temperature increases in the temperature range of $-40^{\circ} \mathrm{C}$ to $100^{\circ} \mathrm{C}$, from about 490 to 427 $\mathrm{kA} / \mathrm{m}$ (which is equivalent to $490-427 \mathrm{emu} / \mathrm{cc}$ or 85-75 Gauss $\cdot \mathrm{cm}^{3} / \mathrm{g}$ ) [13]. Our experimental results confirmed that the metal bonded Co-ferrite composite exhibits the same behavior. This effect, which is due to the magnetic moments on different lattice sites changing differently with temperature, also caused part of the decrease with increasing temperature of the remnant magnetization of the ring-shape ferrite composite. This effect was reversible.

The temperature had another effect on the remanent magnetization when the temperature was raised: specifically it caused partial thermal demagnetization of the sample through release of domain walls from pinning sites. This effect was irreversible. The component of remanence decrease due to the reversible processes at higher temperatures was regained as the sample was cooled back to $22^{\circ} \mathrm{C}$, that component of remanence due to the irreversible process was not regained. Therefore, the thermal energy has only a reversible effect on the measurements at temperatures lower than ambient temperature while having both reversible and irreversible effects on the measurements at temperatures higher than ambient temperature. Hence, in situations where the measurement depends on $M_{R}$, the sensitivity will be dependent on the thermal history since it was last magnetized.

It is known that torsional stresses on a rod or a ring can be considered to be composed of biaxial stresses, in which the two stress axes are perpendicular to each other and at $45^{\circ}$ to the axis of torsion [23]. The change of axial field is caused by the magnetization of the Co-ferrite ring rotating towards the compressive stress direction [12]. Therefore, the magneto-mechanical hysteresis mainly comes from the anisotropy of the ferrite composite. From the existing literature it was found that the anisotropy of $\mathrm{CoO} \cdot \mathrm{Fe}_{2} \mathrm{O}_{3}$ decreased as the temperature increased. The coefficient $K_{1}$ is $90 \mathrm{KJ} / \mathrm{m}^{3}$ at $90^{\circ} \mathrm{C}, 6.6 \mathrm{KJ} / \mathrm{m}^{3}$ at $200^{\circ} \mathrm{C}$, and is negligible at $280^{\circ} \mathrm{C}$ [23]. The coercivity of the metal bonded Co-ferrite composite of the present study, which would depend strongly on anisotropy, was likewise observed to decrease linearly as the temperature increased from -40 to $100^{\circ} \mathrm{C}$. Thus the temperature dependence of the magnetomechanical hysteresis is caused principally by the temperature dependence of the anisotropy. The metal additives $(\mathrm{Ag} / \mathrm{Ni})$ and the bonding treatment of the Co-ferrite composite could also change the anisotropy and the temperature dependence of anisotropy. The coercivity $(\sim 8 \mathrm{kA} / \mathrm{m})$, which is mainly determined by its anisotropy of the present metal-bonded Co-ferrite composite is much lower than that reported for Co ferrite at $22^{\circ} \mathrm{C}(\sim 160 \mathrm{kA} / \mathrm{m})[16-18]$.

It is interesting to note that the magnetomechanical hysteresis effectively disappears above $60^{\circ} \mathrm{C}$ while a sufficient sensitivity still exists at that temperature to give a good signal/noise ratio (about $50 \mathrm{~A} \cdot \mathrm{N}^{-1} \cdot \mathrm{m}^{-2}$ ). Therefore, it is possible to adjust 
the temperature dependent anisotropy of Co-ferrite composites by adjusting the levels of metallic additives $(\mathrm{Ag} / \mathrm{Ni} / \mathrm{Co})$ in order to obtain linear torque response at room temperature.

\section{Summary}

Metal-bonded Co-ferrite composites have been fabricated. These have a combination of saturation magnetostriction in excess of $200 \mathrm{ppm}$ and coercivity of about $8 \mathrm{kA} / \mathrm{m}$, which together give a high initial piezomagnetic coefficient, $(\partial \lambda / \partial H)_{\sigma}$ of $1.3 \cdot 10^{-9} \mathrm{~A}^{-1} \cdot \mathrm{m}$. This is comparable to polycrystalline Terfenol [22], and much larger than Terfenolbased composites consisting of 30 vol.\% Terfenol and 70 vol. $\% \mathrm{NaPO}_{3}$, which had $(\partial \lambda / \partial H)_{\sigma}$ values of typically $2 \cdot 10^{-10} \mathrm{~A}^{-1} \cdot \mathrm{m}$. The magnetomechanical effect under torsional stress measured at room temperature shows that the changes of surface axial magnetic field in response to applied torque were as large as $65 \mathrm{~A} \cdot \mathrm{N}^{-1} \cdot \mathrm{m}^{-2}$, with only a small hysteresis of $\pm 0.5 \mathrm{~N} \cdot \mathrm{m}$. In addition, the metal-bonded composites are mechanically robust, corrosion-resistant, and can be brazed to shafts. Metal-bonded Co-ferrite composites therefore appear to be prime candidates for practical magnetomechanical torque sensors in the range of $\pm 10 \mathrm{~N} \cdot \mathrm{m}$, and for other magnetomechanical sensing and actuating applications.

The temperature dependence of the magnetomechanical effect under torsional strain in metalbonded Co-ferrite composite was investigated. The sensitivity changed from $78 \mathrm{~A} \cdot \mathrm{N}^{-1} \cdot \mathrm{m}^{-2}$ at $-37^{\circ} \mathrm{C}$ to $34.2 \mathrm{~A} \cdot \mathrm{N}^{-1} \cdot \mathrm{m}^{-2}$ at $90^{\circ} \mathrm{C}$ while the magnetomechanical hysteresis decreased from $\pm 1.8 \mathrm{~N} \cdot \mathrm{m}$ at $-37^{\circ} \mathrm{C}$ to negligible above $60^{\circ} \mathrm{C}$. The effects of temperature on magnetomechanical effect under torque at remanence can be described in terms of four processes: changing magnetostriction, changing anisotropy, changing spontaneous magnetization and releasing the pinning sites of domain walls. Metal-bonded Co-ferrite composites show capacity for linear magnetomechanical response to torque which can be achieved by changing the temperature dependence of anisotropy through the use of metallic additives.

These materials have been shown to have sufficient magnetoelastic response (specifically the dynamic range of response that is available as a result of it having greater than $200 \mathrm{ppm}$ magnetotostriction, and the large strain derivative in excess of $\left.1 \cdot 10^{-9} \mathrm{~A}^{-1} \cdot \mathrm{m}\right)$ for certain types of torque sensors and other magnetostrictive sensing and actuating applications [15]. In addition, the materials have adequate mechanical properties (fracture strength
$>69 \mathrm{MPa}$ ) and corrosion resistance for the application. However, little was known about the temperature dependence of the magnetomechanical response in these materials.

\section{Acknowledgments}

Ames Laboratory is operated by the U. S. Department of Energy by Iowa State University under contract No. W-7405-ENG-82. This work was supported by the Office of Energy Research, Office of Computational and Technology Research, Advanced Energy Projects Division.

1. W. J. Fleming, Society of Automotive Engineers, 890482 (1989).

2. I. J. Garshelis, IEEE Trans. Magn. 28, 2202 (1992).

3. I. J. Garshelis and C. R. Conto, J. Appl. Phys. 79, 4756 (1996).

4. Y. Chen, J. E. Snyder, C. R. Schwichtenberg, K. W. Dennis, R. W. McCallum, and D. C. Jiles, 43rd Annual Conf. on Magn. and Magn. Materials (1998).

5. M. J. Sablik and D. C. Jiles, IEEE Trans. Magn. 35, 498 (1999).

6. A. E. Clark, Ferromagnetic Materials 1, E. P. Wohlfarth (ed.), North-Holland, Amsterdam, 531 (1980).

7. F. E. Pinkerton, T. W. Capehart, J. F. Herbst, E. G. Brewer, and C. B. Murphy, Appl. Phys. Lett. 70, 2601 (1997).

8. D. C. Jiles and J. B. Thoelke, J. Magn. and Magn. Mater. 134, 143 (1994).

9. V. Masheva, M. Grigorova, D. Nihtianova, J. E. Schmidt, and M. Mikhov, J. Phys. D: Appl. Phys. 32, 1595 (1999).

10. Y. Chen, J. E. Snyder, C. R. Schwichtenberg, K. W. Dennis, D. K. Falzgraf, D. W. McCallum, and D. C. Jiles, Appl. Phys. Lett. 74, 1159 (1999).

11. J. Smit and H. P. J. Wijn, Ferrites, John Wiley and Sons Inc., New York (1959).

12. C. W. Allen and W. H. Kao, Technical report (THEMISUND-70-11) prepared by the Magnetomechanical group at the University of Notre Dame (1970).

13. Y. Chen, J. E. Snyder, C. R. Schwichtenberg, K. W. Dennis, R. W. McCallum, and D. C. Jiles, IEEE Trans. Magn. 35, 3652 (1999).

14. C. Guillaud, Rev. Mod. Phys. 25, 64 (1953).

15. J. G. Lee, J. Y. Park, and C. S Kim, J. Mater. Sci. 33, 3965 (1998).

16. S. I. Hirano, J. I. Watanabe, and S. Naka, Adv. Ceram. ICF4 15, 65 (1984).

17. S. Chikazumi, Phys. Magnetism, Ch. 7,8, John Wiley and Sons Inc., New York (1964).

18. A. Goldman, Modern Ferrite Technology, Van Nostrand Reinhold, New York (1990).

19. R. M. Bozorth, E. F. Tilden, and A. J. Williams, Phys. Rev. 99, 1788 (1995).

20. P. P. Pulvirenti, D. C. Jiles, R. D. Greenough, and I. M. Reed, J. Appl. Phys. 79, 6219 (1996).

21. P. E. Tannenwald, Phys. Rev. 99, 463 (1955).

22. D. C. Jiles, J. Phys. D: Appl. Phys. 28, 1537 (1955).

23. G. E. Dieter, Mechanical Metallurgy, SI Metric Ed., McGraw-Hill Book Company, New York (1988). 